\title{
Use of flexible nails in children diaphyseal fractures. Five questions and answers
}

\author{
P. Lascombes ${ }^{1}$, P. Journeau ${ }^{2}$, D.A. Popkov ${ }^{3}$ \\ ${ }^{1}$ University of Nancy, France; Geneva University Hospitals, Geneva, Switzerland \\ ${ }^{2}$ Children hospital, Nancy, France \\ ${ }_{3}^{3}$ Ilizarov National Medical Research Centre for Traumatology and Orthopedics, Kurgan, Russian Federation
}

\begin{abstract}
Introduction More than 40 years after the launch of elastic stable intramedullary nailing (ESIN) as a golden standard of the treatment of some fractures in children and adolescents. Material and methods This review is based on answers to five essential questions: The position of ESIN compared with other methods of treatment; The choice of the implants; The indications for ESIN today; How to avoid complications as much as possible? Do we remove the implants or not? Results The aspects of biomechanics, design, indications for ESIN in comparison to other treatment, surgical techniques depending on fractured bones, complications are presented in the article. Conclusion ESIN is an excellent method to fix long bone fractures in children and adolescents. Top one is definitively the fractures of both bones of the forearm, then the diaphyseal fractures of the femur and the tibia before the age to be eligible for a locking nail. However, some unstable fractures cannot be treated conservatively or with a locking nail, and an ESIN remains unstable. In these cases, we are allowed to propose to add an external fixator for 4 to 6 weeks, waiting for a good stabilisation of the fracture.
\end{abstract}

Keywords: pediatric fractures, elastic stable intramedullary nailing, flexible intramedullary nailing

\section{INTRODUCTION}

In a text book dedicated to flexible nailing technique, JP Métaizeau wrote in the preface: "Paradoxically, one of the main issues with ESIN is its apparent simplicity and the excellent patient tolerance of the device. ESIN mechanical principles are easy to understand and the technique itself looks rather straightforward. As a result, many surgeons think that they are perfectly able to perform ESIN procedures with just a basic knowledge of its main principles and without any specific training. This inevitably leads to a number of complications, which are of course readily attributed to the method whereas they are only the result of insufficient training and lack of experience. Curiously, some awkward constructs often yield a successful outcome. This does not mean that one can do anything and that it is just a matter of placing two nails, not bothering about diameter, length, entry point or position of the nails. Poor results are consistently due to incorrect constructs or indications" [1].

\section{MATERIAL AND METHODS}

More than 40 years after the launch of ESIN as a golden standard of the treatment of some fractures in children and adolescents, we would like to answer to five frequent questions routinely asked by surgeons:

- The position of ESIN compared with other methods of treatment;

- The choice of the implants;

- The indications for ESIN today;

- How to avoid complications as much as possible?

- Do we remove the implants or not?

\section{RESULTS AND DISCUSSION}

\section{Why does ESIN exist?}

1.1. ESIN is mini-invasive with a respect of the bone callus repair

For many years, the conservative treatments of fractures have demonstrated that several factors lead to a bone union after fractures in children: 1) the positive role of the hematoma which is not evacuated; 2) the positive effect of the periosteum which is not altered by a surgical approach; 3 ) the alternative micro movements in compression and distraction which are favourable to develop external callus (Fig. 1); 4) the absence of physis injuries and of growth disturbances; 5) and, in addition, a prompt return at school, low hospitalisation costs, and an early return to sport activities.

The respect of these conditions eliminates the use of locking nails and plates in the treatment of fractures in children. If some external fixators (ex-fix) like circular fixators developed by Professor Ilizarov lead to excellent results [2], we admit that the scars, the risks of pin track infections and the presence of the ex-fix are disadvantages to treat fractures compared to ESIN. And finally, if conservative treatments reach the same goal than ESIN, hospitalisation for traction in a femoral shaft fracture or a three-month cast for a fracture of the forearm are not anymore well accepted either by kids or by their parents. 


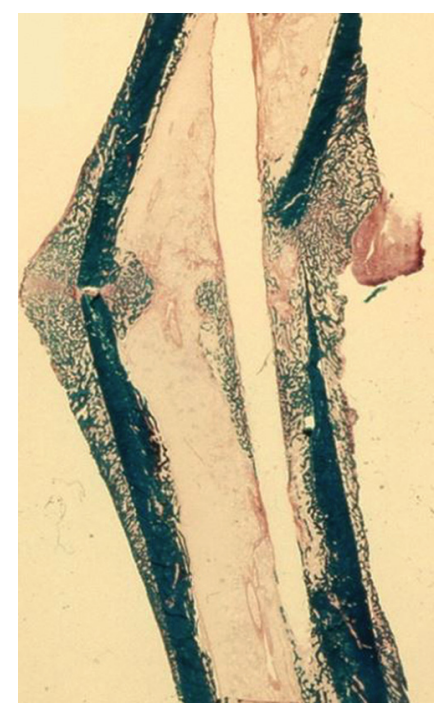

Fig. 1 Fracture of a femur in a rabbit treated with an ESIN procedure. Histologic aspect at D21: the external periosteal callus is of excellent quality. In addition, there is an endosteal callus and also an intramedullary callus along the nail

\subsection{Historical approaches}

Long time ago, surgeons used to fix some fractures with intramedullary straight pins [3] or curved nails. If the use of an elastic curved nail was proposed in Germany as early as 1913 [4], the Romanian Firica developed the concept of two curved and elastic nails to treat a fracture of the femoral diaphysis [5]. In 1979, Métaizeau and Ligier demonstrated the superiority of ESIN over all other methods of fixation in children [6].

\subsection{Economics}

The cost of conservative treatments does not show any advantage versus the ESIN treatment. The comparisons include the duration of hospitalisation, the number of clinical and X-ray controls, some secondary procedures due to displacements under cast, and the out-of-work periods for parents [7].

2. Surgical technique: how to select the appropriate nails?

The performance of nails depends on several criteria: 1) the type of the metal, titanium or stainlesssteel (SS);2) their diameter and their length; 3) the shape of the tip, 4) and their curve.

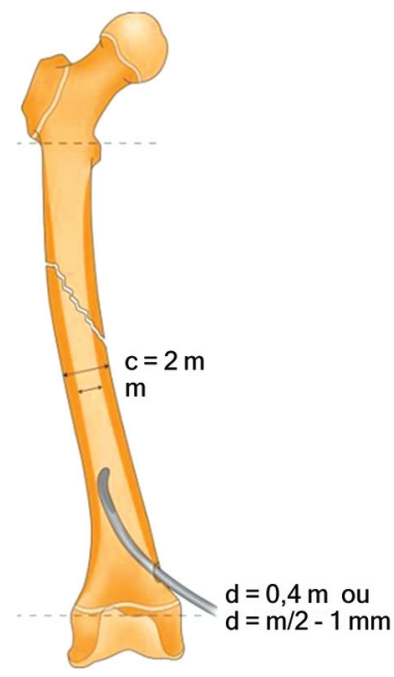

Fig. 2 Formula of the ratio: diameter of the nail (d), diameter of the $\mathrm{MC}(\mathrm{m})$ : $\mathrm{d}=0.4 \times \mathrm{m}[1]$
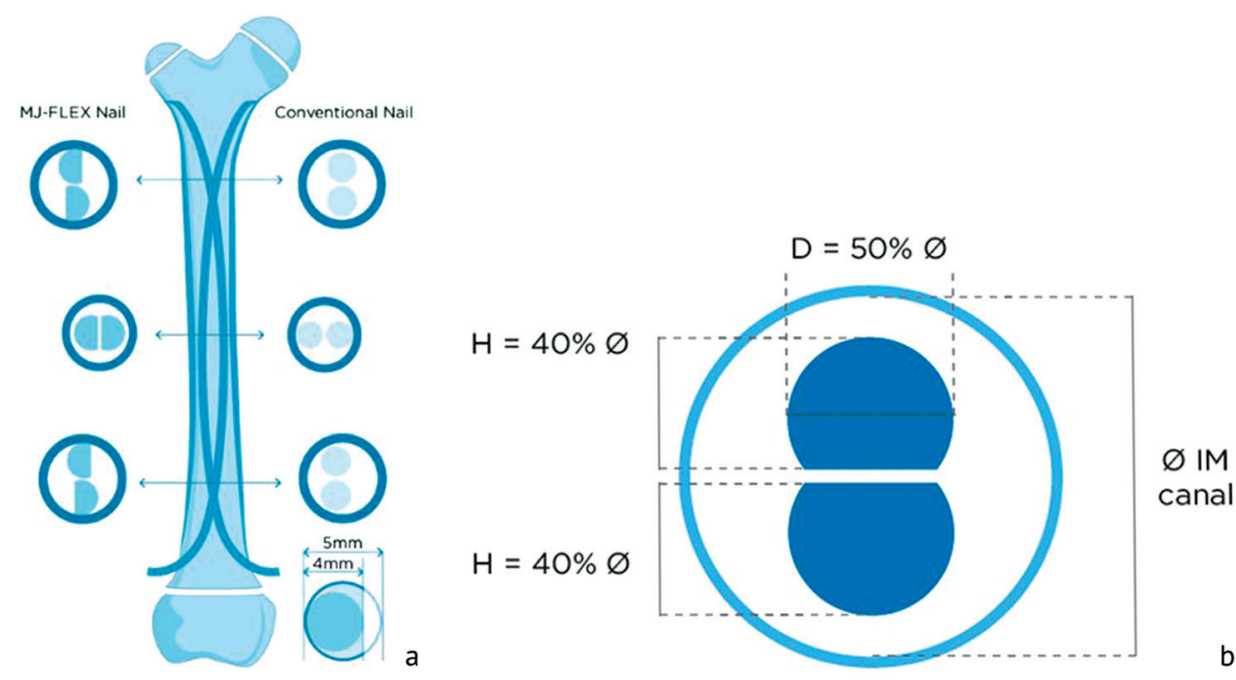

Fig. 3 The MJFlex ${ }^{\circledR}$ nails present a flat area. Comparison between a classic cylindrical 4-mm nail and a 5-mm MJFlex ${ }^{\circledR}$ nail (a). Description of the small and large diameters of the MJFlex® nails, respectively 4 and $5 \mathrm{~mm}(\mathrm{~b})$

\subsection{Titanium or SS?}

During many years, biomechanical studies gave advantages alternatively to either SS or titanium. Regarding their stiffness, SS is clearly stiffer than titanium: for example, stiffness of 3.5-mm SS is almost equivalent to 4-mm titanium [8]. In reverse, titanium, which is more elastic than SS, offers more contact of the nails along the cortex of the intramedullary canal, giving more stability [9]. After 40 years of clinical experience and the use of both types of implants, we are not able to give any real preference to one of both types of implants.

\subsection{Diameter and length}

Most of the nails available on the market have a cylindrical section. The selection of their proper diameter is one of the most important technical points. First, we need to measure the diameter of the medullary canal (MCD) at its narrowest area. The ratio is the percentage of the diameter of the selected nail versus the MCD. It has been demonstrated that mal- and delayed unions are very rare when the ratio is equal or over $40 \%$ per nail in femur and tibia diaphyseal fractures (Fig. 2) [10]. This means that both nails should have a ratio of $40 \%$. Regarding the surface, both nails use only $32 \%$ of the total surface of the medullary canal: but, due to the curve of both nails, this percentage is enough to obtain good results. For the humerus, a good ratio of around $30 \%$ is enough. For the radius and the ulna, there is usually only one nail per bone. The ratio for each nail should also be over $40 \%$ and may sometimes reach $60 \%$.

A new generation of nails has been developed by J.D. Métaizeau. These MJFlex ${ }^{\circledR}$ nails (Orthofix) present with a flat part (Fig. 3). They allow the possibility to insert bigger nails, i.e. $4.5-\mathrm{mm}$ ones for MCD of $10 \mathrm{~mm}$ instead classic $4.0-\mathrm{mm}$ nails. Obviously, the MJFlex ${ }^{\circledR}$ are stiffer than the other cylindric nails [11]. 
Regarding the length of the nails, the attempts to use custom made nails was not a success for many reasons including a heavy stock of nails with many different sizes. So, it is still necessary to cut the nail at the end of the procedure. A nice smooth cutter is mandatory to avoid a too sharp cut which causes soft tissue pain. Because the nails are usually removed, a nail dead end of an appropriate length is let out the bone. But, when the length is too short, the removal can be a nightmare, and when it is too long, the nails can perforate the skin of the patient. We recommend using some impactors with a groove which limit to $12 \mathrm{~mm}$ of dead end for the femur, and to $5 \mathrm{~mm}$ for the forearm.

\subsection{The shape of the tip}

The tip of the nails should be bent either by the surgeon or by the company, and its extreme should be smooth in order to allow the nail to slide against the internal cortex inside the medullary canal (Fig. 4).

\subsection{The curve of the nail}

By definition, each nail should be curved to offer three contacts into the bone. Doing so, both nails contribute to the stability of the fracture. In unstable fractures, long oblique and spiroid and/or with a third fragment, the curve of each nail should be increased to offer a longer part of each nail in contact with the cortex at the level of the fracture (fig. 2).

3. What are the appropriate indications in children diaphyseal fractures?

\subsection{Femoral diaphysis}

It is clear that the development of adolescent locking nails has taken a part of the market of ESIN for the fractures of the femur. They are justified in children above the age of 10 in girls and 12 in boys to limit the growth disturbances. The available diameters of these nails are below $10 \mathrm{~mm}$ and they can be used in children with a MCD of 7 to $8 \mathrm{~mm}$, specifically in severely instable fractures. However, ESIN remains indicated in following fractures:

- As far as the MCD is equal to $10 \mathrm{~mm}$ or below, transverse and short oblique fractures may be successfully treated with ESIN. With the use of the LJFlex ${ }^{\circledR}$ nails, this limit can be lift up to $12 \mathrm{~mm}$. Indications are more related with the diameter of the MC that the body weight of the patient [12].

- Instable fractures of grade 1 and 2 of the Winquist's classification are also treated with ESIN (Fig. 5) [13, 14].

- The upper age limit may correspond to the accessibility for a locking nail. But there is no lower age limit. It is just recommended that, except in cases of polytraumatism, children till 2 to 3 years old may benefit of a conservative treatment.

\subsection{Diaphysis of the tibia}

The indications of ESIN are comparable with the femur, but three differences should be added:

- The conservative treatment is a good method in non- and mild-displaced fractures [15].

- The tibial tuberosity cannot be insult by a locking nail before age 12.5 in girls and 14.5 in boy because the risk of an epiphysiodesis and a secondary knee recurvatum are high.

- The MCD at age 10 reaches frequently $10 \mathrm{~mm}$, which means a limit for a good ESIN.

In the age group between 10-12 (girls) and 12-14 (boys), the use of ESIN with MJFlex ${ }^{\circledR}$ could be an opportunity to alternative treatments [11].

\subsection{Fracture of the forearm}

The quality of the results of the fractures of radius and ulna treated with ESIN and the prompt recovery of the function pushes the surgeons to promote this method in almost all the displaced fractures of the forearm in children and adolescents [16].

In Monteggia's lesion, the primary fixation of the ulna with a flexible nail is a good indication in children and adolescent. The radial head is easily reduced in a second step. In cases of a traumatic bowing of the ulna without an obvious fracture, an ulnar osteotomy is required to be allow the reduction of the radial head, and the osteotomy can be fixed with an ESIN (Fig. 6).
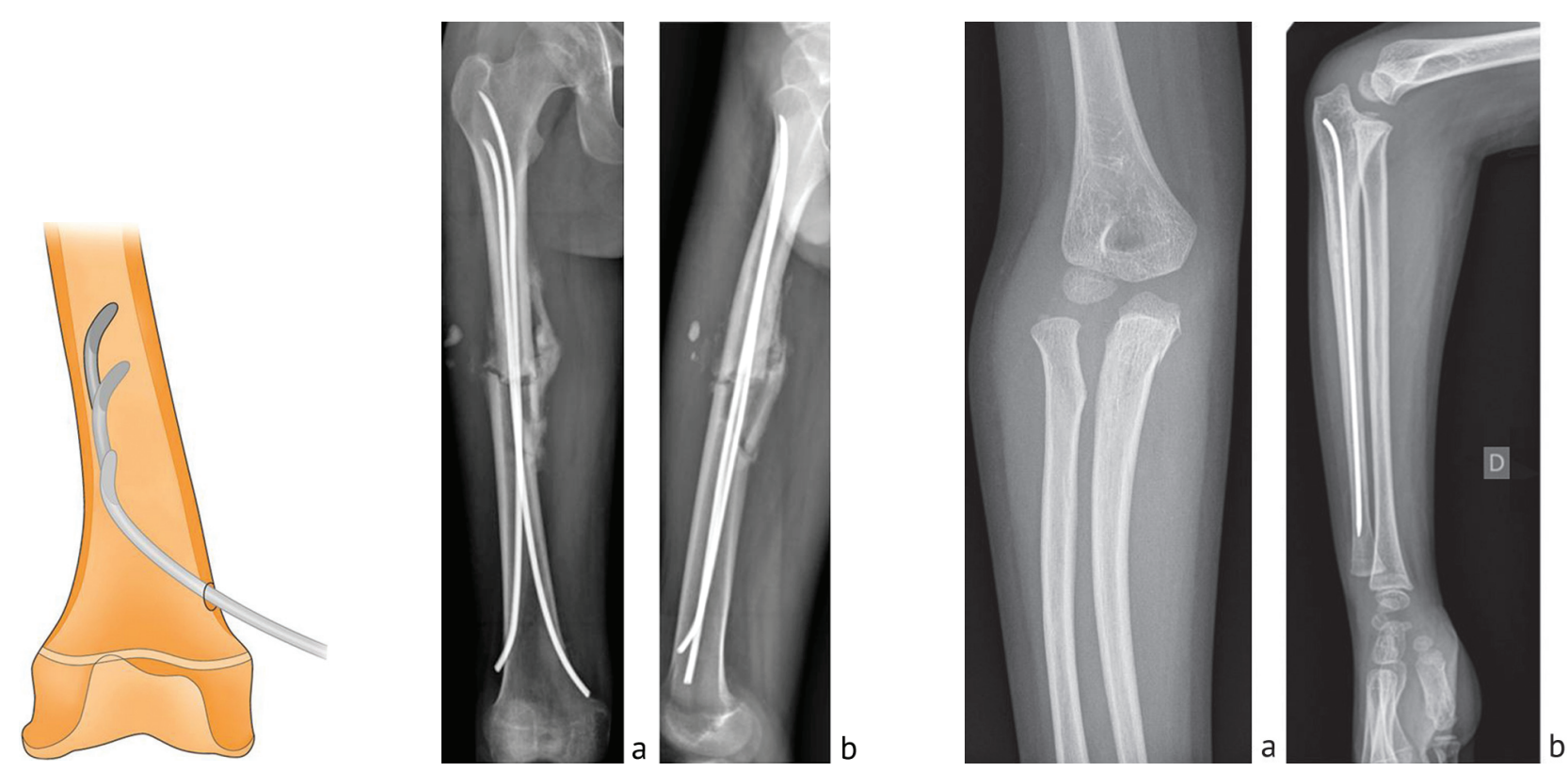

Fig. 4 The bent tip makes easy the progression of the nail to the MC. The extremity is smooth [1]
Fig. 5 Unstable fracture of the femur in an adolescent The third fragment creates a varus-flexum deformity. Use of two $5 \mathrm{~mm}$ MJFlex ${ }^{\circledR}$ nails. On the AP X-ray, the medial nail is oriented laterally as an opposition to the varus deformity (a). On the lateral view, both nails go anteriorly to control the flexum (b) (coll. J-D Métaizeau)
Fig. 6 Girl, 5 years old, Monteggia lesion with a proximal fracture and a traumatic bowing of the ulna (a); osteotomy of the ulna was necessary, and it was fixed with an ESIN (b) 


\subsection{Fracture of the humerus diaphysis}

As conservative treatment is efficient, indications of ESIN are not frequent. However, some situations justify a bone fixation, and ESIN should be proposed in children and adolescent with multiple injuries, severely displaced and instable fractures, and immediate radial nerve palsy [17].

\section{How to avoid complications [18]?}

\subsection{Per operative complication}

Per operative complications should be avoided by an excellent knowledge of the surgical approaches, of the position of the physis, the tendons and the neuro vascular bundles. When the cortex is strong, it is preferable to use a drill than an awl to perforate the cortex and avoid slippage of the bone. On the pre op X-rays, a nondisplaced fragment or a fracture line going to a bone extremity should be detected.

\subsection{Compartmental syndrome}

In a severe trauma, a compartmental syndrome has to be anticipated or at least diagnosed in time. In cases of a difficult reduction of the fracture, as for both bones of the forearm, it is preferable to perform a small surgical approach of the fractures and to reduce them with forceps [19]. Doing so, we may avoid too many manipulations and limit the risk of compartment syndrome.

\subsection{Cutaneous lesion}

They are mainly due to either a sharp cut or a too long extremity of the dead end of the nails. When the fracture is stabilised, the end of the procedure needs some specific cares to the extremity of the nails to prevent post-operative skin lesions. The best position for the nail extremity is to keep it along the bone and not to overbend it (Fig. 7).

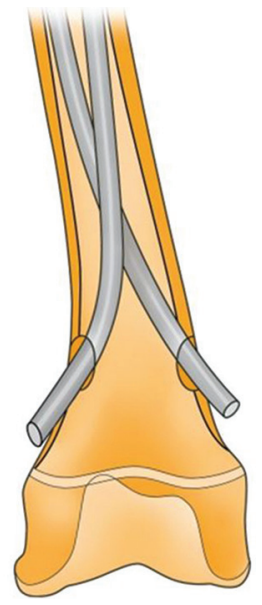

Fig. 7 The section of the nail should be as smooth as possible. The dead end of the nail remains along the bone, and 10 to $12 \mathrm{~mm}$ are outside the bone to facilitate its removal [1]

\subsection{Mal-union}

Mal-union is one of the most frequent complications of ESIN. At follow-ups of 2 to 3 years, most of them correct spontaneously due to growth remodelling, but other cases do not correct perfectly, specifically in adolescents. And of course, it is always better to avoid mal-union.
To obtain a perfect alignment, all the steps of the surgical technique should be carefully observed. First, it is mandatory to respect the recommended ratio as mentioned above [10].

Then, the introduction of the nails should preferably be done far from the fracture. For that reason, a retrograde nailing is used in the femoral fractures of the proximal and middle third, as an antegrade nailing is performed for very distal fractures. A bipolar nailing allows a wellbalanced frame with both nails crossing together above and below the fracture. This goal is more difficult to obtain with unipolar nailing. In such cases, the first nail is normally introduced, pushed through the fracture to continue into the same direction of its introduction. The second nail is introduced in a same way, and at the midshaft level, it is rotated by $180^{\circ}$ in order to be pushed toward the opposite cortex of its introduction. It is not necessary to pre-curve the second nail in an S-shape, a normal C-shape with half a turn is a better option.

And finally, when the fractures are more and more unstable, both nails should be over-curved before their insertion into the bone.

\subsection{Delayed-and non-union}

These complications are usually due to the use of too small nails. As far as the recommended ratio is respected, they should appear very rarely [10].

4.6. Recurrent fracture

The recurrent fractures appear 3 to 18 months after the initial bone union and are typically located at the forearm. This disorder is a well-known complication after conservative treatment. After an ESIN of the radius and the ulna, a delay of 6 months after the fracture is a minimum to recommend the nail removal, and doing so limits the possibility of recurrent fractures.

\section{Nails removal: pro and cons}

The question to remove or not the nails after an ESIN procedure is without a clear answer. Disadvantages of removal are a new surgical procedure with its own risks and troubles. And in some cases, removal of ESIN may be particularly difficult [20]. For that reason, we do not recommend removing the nails in neuro- muscular patients, in cases of benign bone tumors as bone cysts, and in all condition when the ESIN play a role in the prevention of a fracture like some weakness as, of course, osteogenesis imperfecta. But, on the other hand, we can imagine the situation in the future, when a surgeon proposes i.e., a total hip prothesis and sees in the X-rays the presence of two nails which will be definitively very difficult to remove. It could be the same difficult situation in some fractures around the knee with an ESIN in the femur or the tibia. It is why, and after a discussion with the patient and family which starts during the decision of the treatment of the fracture at day 1, our preference is to remove the nails as soon as the fracture is healed, mainly before 6 months postop, except for the forearm which should always be done after 6 months.

\section{CONCLUSION}

We hope that the answers to five questions will help the surgeons to improve the quality of their results. ESIN is an excellent method to fix long bone fractures in children and adolescents. The top one is definitively the fractures of both bones of the forearm, then the diaphyseal fractures of the femur and the tibia before the age that is eligible for a locking nail. However, some unstable fractures can be treated neither conservatively nor with a locking nail, and an ESIN also remains unstable. In these cases, we are allowed to propose to add an external fixator for 4 to 6 weeks, waiting for a good stabilisation of the fracture (Fig. 8) [21, 22]. 


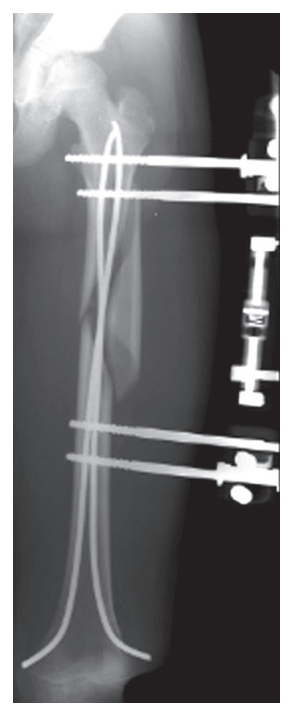

Fig. 8 Boy, 12 years old, spiral fracture with a third fragment of the proximal third of the femur following a mountain bike fall (a). Retrograde ESIN with two 4-mm SS nails. The reduction was not perfect, shortening was present and this condition justified the addition of an external fixator for 6 weeks

\section{REFERENCES}

1. Lascombes P. Flexible Intramedullary Nailing in Children. The Nancy University Manual. Berlin, Heidelberg, Springer-Verlag, 2010 , 317 p. DOI: 10.1007/978-3-642-03031-4.

2. Ilizarov G.A. The principles of the Ilizarov method. Bull. Hosp. It. Dis. Orthop. Inst., 1988, vol. 48, no. 1, pp. 1-11.

3. Rush L.V., Rush H.L. A medullary fracture pin for spring-type fixation as applied to the femur. Miss. Doct., 1949, vol. 27, no. 4, pp. 119-126.

4. Schöne G. Zur Behandlung von Vorderarmfrakturen mit Bolzung [Лечение переломов предплечья штифтами]. Münch. Med. Wochenschr., 1913, vol. 60, pp. 2327-2328. (in German)

5. Firica A., Popescu R., Scarlet M., Dimitriu M., Ionescu V., Protopescu C., Buga M., Constantinescu I., Iliescu N. L'ostéosynthèse stable élastique, nouveau concept biomécanique. Etude expérimentale [Stable elastic osteosynthesis, a new biomechanical conception]. Rev. Chir. Orthop., 1981, vol. 67, no. 1, pp. 82-91. (in French)

6. Métaizeau J.P. L’ostéosynthèse chez l'enfant: techniques et indications [Osteosynthesis in children: techniques and indications]. Rev. Chir. Orthop., 1983, vol. 69, pp. 495-511. (in French)

7. Heffernan M.J., Gordon J.E., Sabatini C.S., Keeler K.A., Lehmann C.L., O'Donnell J.C., Seehausen D.A., Luhmann S.J., Arkader A. Treatment of femur fractures in young children: a multicenter comparison of flexible intramedullary nails to spica casting in young children aged 2 to 6 years. J. Pediatr. Orthop., 2014, vol. 35, no. 2, pp. 126-129. DOI:10.1097/BPO.0000000000000268.

8. Wall E.J., Jain V., Vora V., Mehlman C.T., Crawford A.H. Complications of titanium and stainless steel elastic nail fixation of pediatric femoral fractures. J. Bone Joint Surg. Am., 2008, vol. 90, no. 6, pp. 1305-1313. DOI: 10.2106/JBJS.G.00328.

9. Perez A., Mahar A., Negus C., Newton P., Impelluso T. A computational evaluation of the effect of intramedullary nail material properties on the stabilization of simulated femoral shaft fractures. Med. Eng. Phys., 2008, vol. 30, no. 6, pp. 755-760. DOI: 10.1016/j.medengphy.2007.08.004.

10. Lascombes P., Huber H., Fay R., Popkov D., Haumont T., Journeau P. Flexible intramedullary nailing in children: nail to medullary canal diameters optimal ratio. J. Pediatr. Orthop., 2013, vol. 33, no. 4, pp. 403-408. DOI: 10.1097/BPO.0b013e318285c54d.

11. Denis D., Maucort-Boulch D., Suchier Y., Mamadou T.B., Metaizeau J.D. Biomechanical and Clinical Comparative Study of the New Elastic Stable Intramedullary Nailing "MJ-FLEX Orthofix". J. Pediatr. Orthop., 2020, vol. 40, no. 3, pp. 149-155. DOI: 10.1097/BPO.0000000000001206.

12. Shaha J., Cage J.M., Black S., Wimberly R.L., Shaha S.H., Riccio A.I. Flexible intramedullary nails for femur fractures in pediatric patients heavier than 100 pounds. J. Pediatr. Orthop., 2018, vol. 38, no. 2, pp. 88-93. DOI: 10.1097/BPO.0000000000000775.

13. Winquist R.A., Hansen S.T. Jr. Comminuted fractures of the femoral shaft treated by intramedullary nailing. Orthop. Clin. North Am., 1980, vol. 11, no. 3, pp. 633-648.

14. Luo Y., Wang L., Zhao L.H., Wang Y.C., Chen M.J., Wang S., Ma Q.C. Elastic stable titanium flexible intramedullary nails versus plates in treating low grade comminuted femur shaft fractures in children. Orthop. Surg., 2019, vol. 11, no. 4, pp. 664-670. DOI: 10.1111/os.12514.

15. Canavese F., Botnari A., Andreacchio A., Marengo L., Samba A., Dimeglio A., Pereira B., Mansour M., Rousset M. Displaced tibial shaft fractures with intact fibula in children: nonoperative management versus operative treatment with elastic stable intramedullary nailing. J. Pediatr. Orthop., 2016, vol. 36, no. 7, pp. 667-672. DOI: 10.1097/BPO.0000000000000528.

16. Lascombes P., Prevot J., Ligier J.N., Metaizeau J.P., Poncelet T. Elastic stable intramedullary nailing in forearm shaft fractures in children: 85 cases. J. Pediatr. Orthop., 1990, vol. 10, no. 2, pp. 167-171.

17. O'Shaughnessy M.A., Parry J.A., Liu H., Stans A.A., Larson A.N., Milbrandt T.A. Management of paediatric humeral shaft fractures and associated nerve palsy. J. Child. Orthop., 2019, vol. 13, no. 5, pp. 508-515. DOI: 10.1302/1863-2548.13.190012.

18. Lascombes P., Nespola A., Poircuitte J.M., Popkov D., de Gheldere A., Haumont T., Journeau P. Early complications with flexible intramedullary nailing in childhood fracture: 100 cases managed with precurved tip and shaft nails. Orthop. Traumatol. Surg. Res., 2012, vol. 98, no. 4, pp. 369-375. DOI: 10.1016/j. otsr.2011.11.011.

19. Pandya N.K., Edmonds E.W., Mubarak S.J. The incidence of compartment syndrome after flexible nailing of pediatric tibial shaft fractures. J. Child. Orthop., 2011, vol. 5, no. 6, pp. 439-447. DOI: 10.1007/s11832-011-0374-y.

20. Ferry S.T., Dahners L.E. Flexible intramedullary nail removal using a broken screw removal set. J. Orthop. Trauma, 2006, vol. 20, no. 5, pp. 351-353. DOI: 10.1097/00005131-200605000-00009.

21. El-Alfy B., Ali A.M., Fawzy S.I. Comminuted long bone fractures in children. Could combined fixation improve the results? J. Pediatr. Orthop. B, 2016, vol. 25, no. 5, pp. 478-483. DOI: $10.1097 /$ BPB.0000000000000303.

22. Ertürk C., Altay M.A., Bilge A., Altay N., Ișikan U.E. Do additional intramedullary elastic nails improve the results of definitive treatment with external fixation of open tibia fractures? A prospective comparative study. Orthop. Traumatol. Surg. Res., 2013, vol. 99, no. 2, pp. 208-215. DOI: 10.1016/j. otsr.2012.12.008.

Received: 17.05.2021

\section{Information about the authors:}

1. Pierre Lascombes, Honorary Professor University of Nancy, France; Past Professor, University of Geneva, Switzerland, Email: pierrelascombes@gmail.com

2. Pierre Journeau, M.D., Children hospital, Nancy, France

3. Dmitry A. Popkov, M.D., Ph.D., Professor of RAS, correspondent member French Academy of Medical Sciences,

Ilizarov National Medical Research Centre for Traumatology and Orthopedics, Kurgan, Russian Federation, ORCID: 0000-0002-8996-867X,

Email: dpopkov@mail.ru 